\section{A precise method of measuring fixational eccentricity using the Maxwell spot centroid*}

\author{
GILLRAY L. KANDEL and HAROLD E. BEDELL \\ Rensselaer Polytechnic Institute, Troy, New York 12181
}

An improved version of a method which uses the Maxwell spot to measure eccentricity of fixation is described and discussed. The method determines the centroid of the macula psychophysically and locates the position of this centroid with respect to the point the $O$ uses for fixation. The distance between these two points is a measure of eccentricity of fixation. It is estimated that the present method has an instrumental error of about $0.1 \mathrm{deg}$.

When the eye of an $\mathrm{O}$ having normal macula pigment is exposed once a second to dichromatic light followed by neutral light, he will see his visual field marred by a blemish during each dichromatic phase. The blemish measures about 0.5 to $2.5 \mathrm{deg}$, is approximately circular, and appears in the center of the visual field. If the dichromatic light is purple, Os describe the blemish as darker or redder during that phase. Some Os are also able to perceive a blemish that appears lighter or slightly greenish during the neutral phase. These blemishes are the Maxwell spots (Ms), which Maxwell attributed to the differential transmission of the macular pigment. 1 (We are inclined to believe that differential afterimages also play a role in the spot's formation.) For this reason, the spot has been used as a psychophysical indicator of the location of the macula within the visual field. In this capacity, and on the assumption that the center of the macula corresponds to the center of the fovea, it has found considerable favor among investigators studying eccentricity of fixation. Along with the Haidinger brushes, another entoptic phenomenon, it ranks as one of two leading methods to measure psychophysically the eccentricity of fixation of functional amblyopes. However, compared to the Haidinger brush, the Ms method is a remarkably simple affair. Even in unskilled hands, if an $O$ can estimate the distance between his Ms' center and his point of fixation, the measurement of eccentricity of fixation can be made

*This research was supported by National Eye Institute Grant EY00800 to the first author. We thank Professor Fred Billmeyer, Jr., R. Marcus, E. D. Campbell, and D. Phillips of the Rensselaer Color Measurement Laboratory of Rensselaer Polytechnic Institute for help and advice in selecting filters and determining the chromaticity coordinates of these filters. The authors also owe a debt of gratitude to Paul E Grattan OD (Waterford, New York), our project consultant, who graciously lent us a Maxwell spot stimulator, which became the basis for the one described here. and half a neutral filter of equal photometric density, is interposed between the projector and the GGS
The dichromatic filter (whose chromaticity coordinates are $\mathrm{x}=.173$, $\mathrm{y}=.034$ ) comprises Roscolene Filters 861 and 839 , while the neutral filter (coordinates $\mathrm{x}=.261, \mathrm{y}=.262$ ) comprises Roscolene Filter 883. (Roscolene filter materials are available in sheet form from Edmund Scientific Co, Barrington, New Jersey 08007.) The disk is rotated by a $30-$ to $45-\mathrm{rpm}$ motor so that the projector's light passes through each half of the filter disk as it rotates. The projector, filter disk, and motor are all enclosed in a lightproofed box, one side of which is the GGS.

Although the purpose of the second projector (OHP) could be accomplished by other arrangements, the authors have found that the 90-deg reflecting type, commonly called an overhead projector, is quite adequate. These instruments permit easy access to, and movement of, an object whose image is to be projected. In this device, the object consists of an opaque screen whose area is great enough to occlude all light from the OHP. The screen, however, has a central opening over which an adjustable iris diaphragm is securely mounted. When properly focused and positioned, the OHP produces an image of a disk of light on the GGS. The size and position of the disk are both adjustable, and its illuminance can be controlled by the crossed Polaroid filters mounted in the projector's beam.

To measure fixational eccentricity, an $O$ is seated at a suitable distance facing the GGS. The OHP is placed in a position so that $O$ can maneuver the opaque screen. The aperture of the iris diaphragm is brought into sharp focus

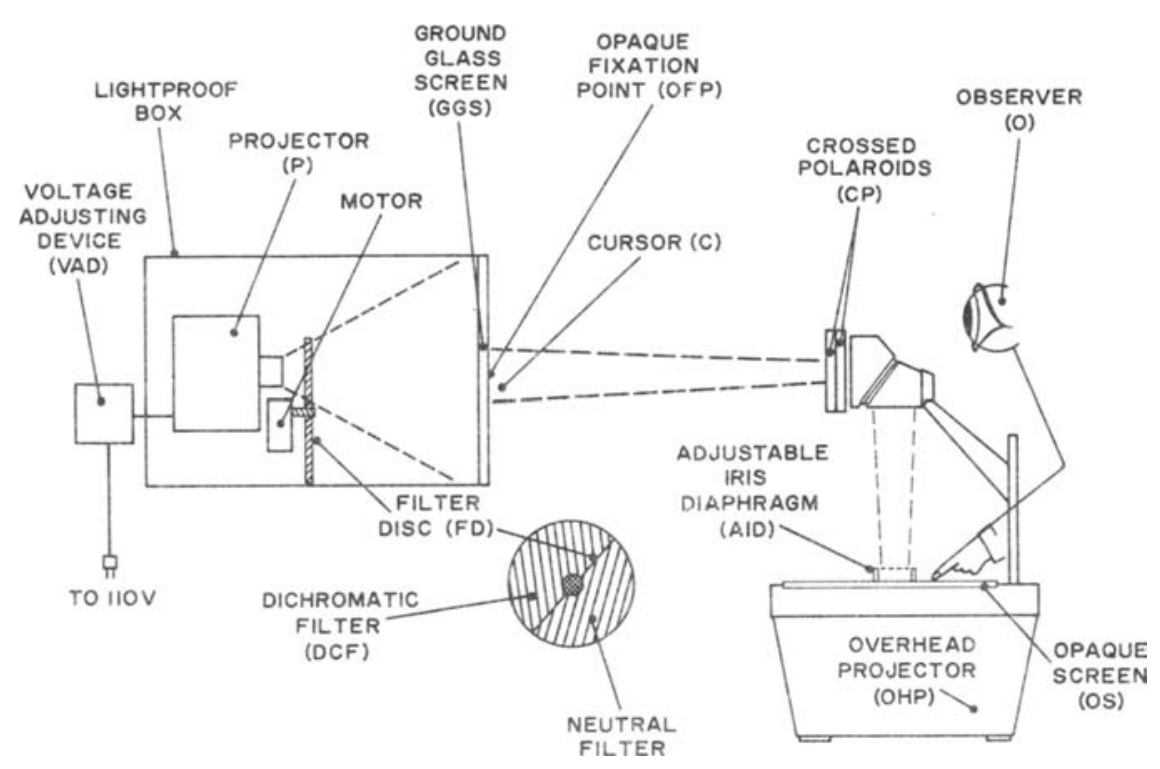

Fig. 1. Schematic view of apparatus. 
Table 1

Determination of Instrumental Error: Average Error of Placement Between Cursor Center and Pseudo-Ms Centroid

\begin{tabular}{|c|c|c|c|c|}
\hline & & $\begin{array}{c}\text { Eye } \\
\text { Tested }\end{array}$ & $\begin{array}{l}\text { (Average) } \\
\text { Error in } \\
\text { Degrees }\end{array}$ & $\begin{array}{c}\text { Number } \\
\text { of } \\
\text { Measurements }\end{array}$ \\
\hline \multirow[t]{7}{*}{ Adult } & Practiced & & & \\
\hline & MHG & Right & .10 & 4 \\
\hline & HEB & Right & .04 & 4 \\
\hline & GLK & Left & .03 & 4 \\
\hline & Unpracticed & & & \\
\hline & $\mathrm{PCL}$ & Right & $.08 *$ & 1 \\
\hline & JNG & Right & $.02^{*}$ & 1 \\
\hline \multirow[t]{5}{*}{ Children } & Unpracticed & & & \\
\hline & SNG (6 years) & Both & .09 & 2 \\
\hline & MNJ (8 years) & Right & .12 & 3 \\
\hline & KNJ (9 years) & Right & .16 & 3 \\
\hline & MNG (4 years) & Both & .13 & 4 \\
\hline
\end{tabular}

*This value represents the first measurement made on the instrument by the $O$. $+E$ moved cursor in response to $O$ 's instructions.

onto the GGS. (The selected distance between the $O$ and GGS depends upon the $O$ 's acuity. We find that at a distance of 85 in., it is possible for Os with normal acuity to successfully fixate the opaque fixation point. At this distance, the point subtends less than $2 \mathrm{~min}$ of visual angle.) The eye contralateral to the one to be tested is occluded. The viewing room is darkened, the motor is started, the projector is turned on, and its voltage is adjusted upward. The $O$ is first asked to look at the GGS and to describe what is seen. Most Os can see the Ms when screen luminance reaches $65 \mathrm{fL}$. Occasionally, $O$ reports the spot's intensity diminished or its outline faded after a few minutes of continuous viewing. In such cases, the $O$ is returned to normal room light for a minute or so.

To determine the spot's location with respect to the $O$ 's fixation point, the OHP is turned on and the crossed Polaroids adjusted to project a just visible disk of light onto the GGS face. The $O$ first adjusts the size of the diaphragm so that the projected disk is about equal to the diameter of his Ms. This projected disk is then used as a cursor (C), which is moved laterally or to and fro by adjustments of the opaque screen. In this way, the $\mathrm{C}$ is made to coincide with $O$ 's Ms while he fixates the point on the GGS. Readjustment of the crossed Polaroids, the voltage, and diaphragm, as well as minor changes in C's position, are then made.

Some Os find it helpful to fully occlude the $\mathrm{C}$ momentarily so as to permit the viewing of the undisturbed Ms. Under such circumstances, the $O$ must be cautioned to wait until the afterimage of the $\mathrm{C}$ itself disappears. If this maneuver is used, the $O$ is instructed to look for an absence of what appears to be movement between the spot and $\mathrm{C}$ at the moment that the $\mathrm{C}$ is made to reappear. Slight shrinkage or expansion of the $\mathrm{C}$ by the well-fixated eye is taken as a sign of its accurate placement. When the $O$ is satisfied with his setting, the size of the $C$ and the position of its center are noted. Knowing these and the direction of the C's center from the fixation point as well as the O-to-GGS distance, the amount of eccentricity and its meridian expressed in angles can be determined easily with simple trigonometry.

The above method is similar to Flom and Weymouth's (1961). However, the present technique overcomes several limitations and disadvantages of theirs. For example, their fixation point subtended in excess of $10 \mathrm{~min}$ and therefore could hardly be expected to hold an O's visual fixation accurately. Also, they located the Ms by setting opaque strips tangent to the spot's horizontal and

Table 2

Eccentricities of Fixation of Os Measured by a Maxwell Spot Technique

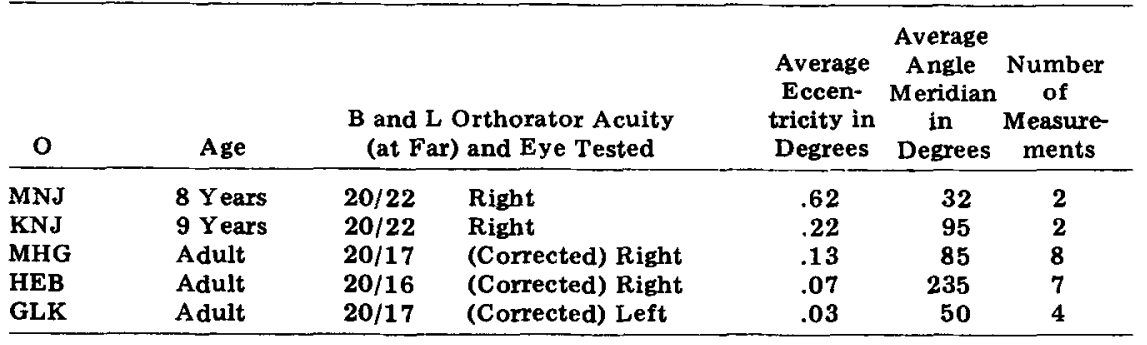

vertical borders. In addition to the fact that these opaque strips block out parts of the light stimuli which evoke the spot, Os frequently do not see the spot as round, regular, or with clearly defined edges. The Flom-Weymouth method assumes the spot to be a regular figure with clearly defined edges. For these reasons, the use of opaque strips introduces errors of unknown magnitude in the location of the Ms centroid.

The instrumental error of the present method was estimated by the following procedure. The GGS was backlighted with steady purple light from the filter. With a third projector, a pseudo-Ms of .75 or $1.5 \mathrm{deg}$ diam was imaged onto the front of the GGS. This pseudospot was an irregular and defocused blotch of reddish light. The resulting image was deemed to very closely mimic the appearance of the Ms of one $O$. Next, each of three practiced and six unpracticed Os adjusted and centered the $\mathrm{C}$ on the pseudo-Ms (the latter's center was determined by a center-of-gravity technique). The distances between the centers of the pseudo-Ms and the $C$ are expressed as average errors in degrees in Table 1. It is most gratifying that the two unpracticed adults and four children made errors of about the same magnitude as the practiced Os. While the youngest child had to be assisted in controlling the C's movement, we believe that with the addition of hand controls for the $C$, this child would have managed to move the $\mathrm{C}$ himself.

Our work with this technique has been largely confined to young adults with normal or functionally amblyopic vision. It would seem that this method will find its greatest application in the laboratory. However, the ease of its use and the precision of its measurements suggest that a device of this type might be adapted either to the training of, or the measurement of, the fixation of younger amblyopic patients. To test this possibility, we measured the fixational eccentricities of our 8- and 9-year-old Os. Their fixational eccentricities, together with those of the three highly practiced Os, are contained in Table 2 . These values show that this instrument, even in its laboratory form, can be operated successfully by youngsters.

FLOM, M. C. \& WEYMOUTH, F. W Centricity of Maxwell's spot in strabismus and amblyopia. Archives of Ophthalmology, 1961, 66, 260-268.

GRAHAM, C. $\dot{H}$. Discriminations that depend on wavelength. In C. H. Graham (Ed.), Vision and visual perception. New York: Wiley, 1965. Pp. 350-369.

\section{NOTE}

1. Footnote 9 of Chapter 12 of Graham (1965) provides an excellent starting bibliography on the Maxwell spot. 